\title{
The Impact of Adding Magnesium Sulfate to Bupivacaine versus Bupivacaine Alone in Fascia Iliaca Compartment Block in Burn Patients Undergoing Skin Grafting Procedures; Comparative Study
}

\author{
Sameh Ghareeb* ${ }^{(0)}$, Yassen M. Amr, Rokaya Mohamed, D. G. Diab \\ Department of Anesthesia and Surgical Intensive Care, Faculty of Medicine, Mansoura University, Mansoura, Egypt \\ Email: *sameh926@yahoo.com
}

How to cite this paper: Ghareeb, S., Amr, Y.M., Mohamed, R. and Diab, D.G. (2021) The Impact of Adding Magnesium Sulfate to Bupivacaine versus Bupivacaine Alone in Fascia Iliaca Compartment Block in Burn Patients Undergoing Skin Grafting Procedures; Comparative Study. Open Journal of Anesthesiology, 11, 99-111.

https://doi.org/10.4236/ojanes.2021.114010

Received: February 4, 2021

Accepted: April 17, 2021

Published: April 20, 2021

Copyright $\odot 2021$ by author(s) and Scientific Research Publishing Inc. This work is licensed under the Creative Commons Attribution International License (CC BY 4.0).

http://creativecommons.org/licenses/by/4.0/

\begin{abstract}
Purpose: The purpose of the study is to evaluate the analgesic effect of adding magnesium sulfate to bupivacaine in Fascia Iliaca Compartment Block (FICB). Patients and Methods: Ninety-six burn patients scheduled for skingrafting procedures were allocated into two equal groups. After induction of general anaethesia, forty-eight patients received US guided FICB using $35 \mathrm{ml}$ bupivacaine $0.25 \%+5 \mathrm{ml}$ isotonic sodium chloride solution with a total volume of $40 \mathrm{ml}$. The other forty-eight patients received $35 \mathrm{ml}$ bupivacaine $0.25 \%+250 \mathrm{mg}$ of magnesium sulfate with a total volume of $40 \mathrm{ml}$. Results: Total postoperative pethidine consumption in the first $24 \mathrm{~h}$ post-operative showed a highly statistically significant decrease in the magnesium group in comparison to the bupivacaine group. Conclusion: Adding magnesium sulfate to bupivacaine in FICB in skin grafting procedures decreased the pain scores post-operative, delayed the first request of analgesia and reduced the total analgesic consumption in the first $24 \mathrm{~h}$ post-operative without any significant side effects.
\end{abstract}

\section{Keywords}

Bupivacaine, Magnesium Sulfate, Fascia Iliaca Block

\section{Introduction}

Patients who survive severe burns undergo multiple reconstructive surgeries to re-establish function. These operations involve placement of split-thickness skin 
graft [1]. Often, the site of the harvested graft is the most painful part of the procedure. Because of this, regional nerve blockade has been used to provide better analgesia [2].

Skin graft donor sites are usually chosen from the lateral and/or anterior upper part of the thigh. These areas coincide with the distribution of the lateral femoral cutaneous nerve (LFCN) and femoral nerve [3]. The fascia iliaca compartment block (FICB) is effective in producing the simultaneous blockade of both LFCN and femoral nerve [4]. The local anesthetics (LA) should spread between the iliacus muscle and the fascia iliaca [5].

Magnesium is a physiologic cation that potentiates neuromuscular and peripheral nerve blockade. It has been shown to have antinociceptive effects in animal and human models. It blocks the NMDA receptors and their associated calcium channels preventing calcium influx [6]. Magnesium also prevents catecholamine release from the adrenal and peripheral nerve endings producing a sympatholytic action [7].

\section{Patients and Methods}

This is a double blind prospective randomized controlled study that was conducted for one year (from May 2018 to May 2019) in Plastic Surgery CenterMansoura University. After approval from the Institutional Research Board (IRB) (Code Number: MS.18.06.166), Faculty of Medicine, Mansoura University, 96 burn patients with second- or third-degree burn, American Society of Anesthesiologists physical status grade I and grade II, aged between 21 and 60 years of either sex were included in the study.

Patients with neuromuscular diseases, hematological diseases, psychiatric diseases, local skin infection or sepsis at site of the block, known intolerance or hypersensitivity to the study drugs, uncompensated heart, liver or kidney diseases were excluded.

The primary outcome was the total dose of pethidine consumed in the first $24 \mathrm{~h}$ post-operative. The secondary outcomes were the intraoperative and post-operative hemodynamic stability, post-operative visual analogue scale (VAS) score, the time of first request of rescue analgesics, post-operative Ramsay sedation scale (RSS) score and the simplified post-operative nausea and vomiting (PONV) impact scale score.

Eligible 96 patients were randomly allocated by closed envelope method according to the type of the injected local anesthetic solution into 2 equal groups. Bupivacaine Group ( $B$ group) ( $n=48)$ : patients received $35 \mathrm{ml}$ bupivacaine $0.25 \%+5 \mathrm{ml}$ isotonic sodium chloride solution with a total volume of $40 \mathrm{ml}$.

Magnesium Group ( $M$ group) $(n=48)$ : patients received $35 \mathrm{ml}$ bupivacaine $0.25 \%+250 \mathrm{mg}$ of magnesium sulfate with a total volume of $40 \mathrm{ml}$. Double blindness was ensured through the usage of equal volumes of injectates for both groups in similar syringes prepared by an anesthetist not involved in the study. All blockades were performed by the same trained anesthetists who took part in this study. 
All patients were assessed preoperatively by history, physical examination and laboratory investigations. The study protocol and fascia iliaca compartment block procedure were explained to all patients. All patients became familiar with the use of visual analogue scale (VAS) score. Patients fasted $6-8 \mathrm{~h}$ before the time of surgery.

On arrival of the patient to the preparation room, routine monitoring was applied, peripheral IV cannula (20G) was inserted and ringer solution started to be infused. All patients were premedicated using midazolam $0.03 \mathrm{mg} / \mathrm{kg}$ IV.

GA was induced using IV propofol $(2-3 \mathrm{mg} / \mathrm{kg})$, IV fentanyl $(1 \mu / \mathrm{kg})$ and atracurium besylate $(0.6 \mathrm{mg} / \mathrm{kg})$ to facilitate intubation. Then, the patient was mechanically ventilated using volume control mode with TV (6 - 8) $\mathrm{ml} / \mathrm{kg}$, RR (10 - 14) breath/min and I: E ratio (1:2) to maintain $\mathrm{EtCo}_{2}(30-35) \mathrm{mmHg}$.

Anesthesia was maintained using minimum alveolar concentration of isoflurane $1.2 \%$ and $60 \%$ air in $\mathrm{O} 2$ mixture with top up doses of atracurium. Additional IV fentanyl doses ( 25 microgram) were given according to hemodynamics (Blood pressure \& Heart rate $>20 \%$ of the basal). Intraoperative fentanyl consumption was calculated. Intraoperative IV fluids and blood (if needed) were given per body weight and according to the intraoperative loss.

Fascia iliaca compartment block was performed after induction of general anesthesia and approximately 10 - 15 min before skin incision.

All patients were extubated at the end of surgery after neuromuscular reversal with administration of neostigmine $(0.04 \mathrm{mg} / \mathrm{kg})$ and IV atropine $(0.02 \mathrm{mg} / \mathrm{kg})$ and fulfilling the criteria of extubation.

The patient was properly positioned in supine position. The superficial US probe (Philips, ClearVue350) was placed on the patient in a transverse plane over the inguinal crease. A 22-gauge Quincke needle was introduced via an inplane approach. The target was to lay the needle's tip just underneath the fascia iliaca.

After reliable negative aspiration, we injected $1-2 \mathrm{ml}$ of local anesthetic (LA) to confirm the correct injection plane. This formed a small bleb or "lens" deep to the fascia iliaca. Gently we advanced the needle into this bleb and further LA was injected. Forty $\mathrm{ml}$ of LA were injected between the iliacus muscle and the fascia iliaca for optimal distribution around the nerves.

In the operating room, monitoring of ECG, heart rate (HR), $\mathrm{SpO}_{2}, \mathrm{EtCo}_{2}$ and non-invasive blood pressure (NIBP) was done. Base line values of $\mathrm{HR}, \mathrm{SpO}_{2}$ and MAP were collected just before induction of anesthesia, after induction and at skin incision (10 - 15 min after the block). Then, recording was done every 15 min till the end of surgery.

After admission of the patients into the post anesthesia care unit (PACU) and their transfer into the ward, these data were recorded at $1,2,4,8,16$ and 24 hours post-operatively:

- HR and MAP.

- Pain intensity using visual analogue scale (VAS): in which, the patient is told 
to mark the strength of pain he feels at one point along the length of a $10-\mathrm{cm}$ line. The two ends of the scale represent "no pain" on the left end of the scale $(0 \mathrm{~cm})$ and the "worst pain" on the right end of the scale $(10 \mathrm{~cm})$. [8] When the patient experienced pain (score $>3$ ), a bolus dose of IV pethidine 0.25 $\mathrm{mg} / \mathrm{kg}$ was administered and repeated every 15 minutes till visual analogue scale score $\leq 3$ was attained.

- Ramsay sedation score (RSS) [9] where;

$1=$ Anxious, agitated, restless.

$2=$ Awake, but tranquil and cooperative.

$3=$ Responsive to commands only.

$4=$ Brisk response to light glabellar tap or loud auditory stimulus.

$5=$ Sluggish response to light glabellar tap or loud auditory stimulus.

$6=$ No response to light glabellar tap or loud auditory stimulus.

The time of first request of analgesia was recorded from the time of arrival to PACU. The total dose of pethidine (mg) consumed in the first 24-hour postoperative was calculated in both groups. Postoperative complications like nausea and vomiting (PONV) were recorded using the simplified PONV impact scale where clinically important PONV was defined as a total score of more than 4 [10]. PONV was treated using primperan $10 \mathrm{mg}$ IV.

Sample size calculation: A Priori G-power analysis was done to estimate study sample size using a previous study: magnesium prolongs the duration of analgesia after a bupivacaine fascia iliaca compartment block [11] in which tramadol was used postoperative, and by calculating the equilivant doses of tramadol and pethidine $(0.4 \mathrm{mg}$ pethidine equals $0.2 \mathrm{mg}$ tramadol as regards oral morphine equivalent). A power of $80 \%$ was estimated with type I error of 0.05 to get an analgesic difference between groups of approximately $30 \%$ to yield of total sample size of 91 cases. A drop out of 5\% of cases was expected. Therefore, a total number of 96 cases were needed (48 cases per group).

Statistical analysis: The statistical analysis of the collected data was done by IBM's SPSS statistics (Statistical Package for the Social Sciences) for windows (version 25, 2017). The normality of the data distribution was checked by Shapiro-Wilk test. Student $\mathrm{t}$ test and Mann-Whitney were used for normally and abnormally distributed continuous data respectively. Chi square test was used for categorical data using the crosstabs function. Every test was conducted with $95 \%$ confidence interval. Probability $(\mathrm{P})$ value $<0.05$ was considered statistically significant. SPSS' chart builder and Microsoft Excel for windows 2019 were used for generating charts.

\section{Results}

This double blind prospective randomized controlled study was conducted on 96 patients ASA I, II of either sex between 21 and 60 years who were scheduled for skin grafting procedures for treatment of second- or third-degree burn (study flowchart Figure 1). 
There were no statistically significant differences between the two groups regarding demographic data, BMI, ASA classification and duration of surgery (Table 1). As regard intraoperative haemodynamics (HR and MAP) there were no statistically significant differences between the 2 studied groups.

As regard postoperative HR, there was a statistically significant decrease in the magnesium group in comparison to the bupivacaine group at 4 and 8 hours postoperative (Figure 2).

As regard postoperative MAP, there was a statistically significant decrease in the magnesium group in comparison to the bupivacaine group at 4,8 and 16 hours postoperative (Figure 3).

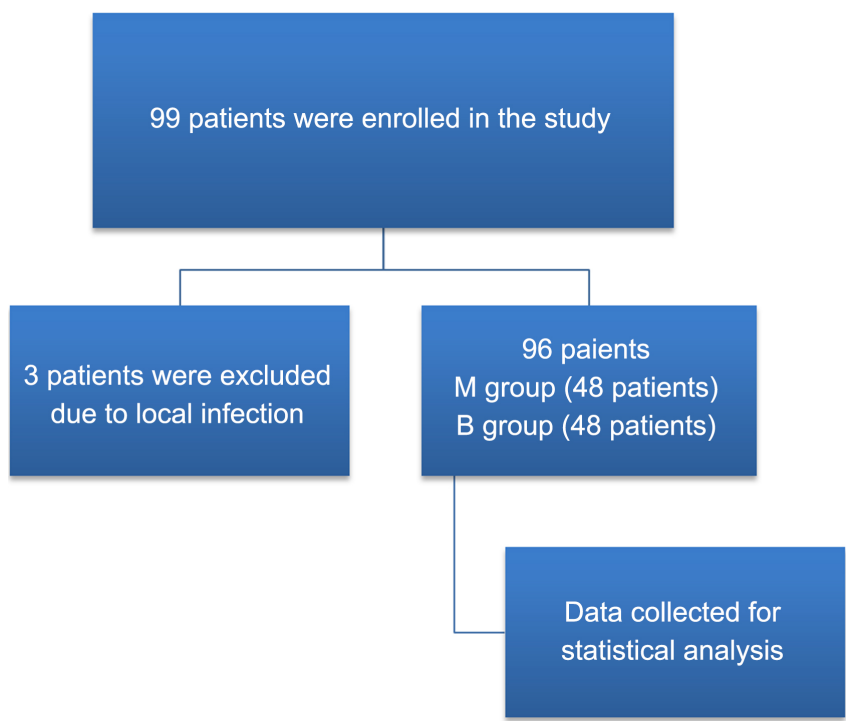

Figure 1. Flow chart for patients participating in the study.

Table 1. Demographic data.

\begin{tabular}{cccc}
\hline & $\begin{array}{c}\text { Group B } \\
(\mathbf{n}=48)\end{array}$ & $\begin{array}{c}\text { Group M } \\
(\mathbf{n}=48)\end{array}$ & P value \\
\hline Age (years) & $38.73 \pm 9.15$ & $37.40 \pm 10.67$ & 0.51 \\
BMI (kg/m $)$ & $27.18 \pm 1.98$ & $26.73 \pm 3.27$ & 0.41 \\
Sex & $28(58 \%)$ & $27(56 \%)$ & 1 \\
Male No. (\%) & $20(42 \%)$ & $21(44 \%)$ & \\
Female No. (\%) & & $35(73 \%)$ & 0.66 \\
ASA & $33(69 \%)$ & $13(27 \%)$ & 0.52 \\
I No. (\%) & $15(31 \%)$ & $68.75 \pm 9.37$ & \\
II No. (\%) & $67.65 \pm 7.09$ & & \\
Duration of surgery (min) & & & \\
\hline
\end{tabular}

Group B: Bupivacaine group, Group M: Magnesium group, BMI: Body mass index, ASA: American Society of Anaesthesiologists. Data are expressed as mean \pm SD, number, $\%$. 


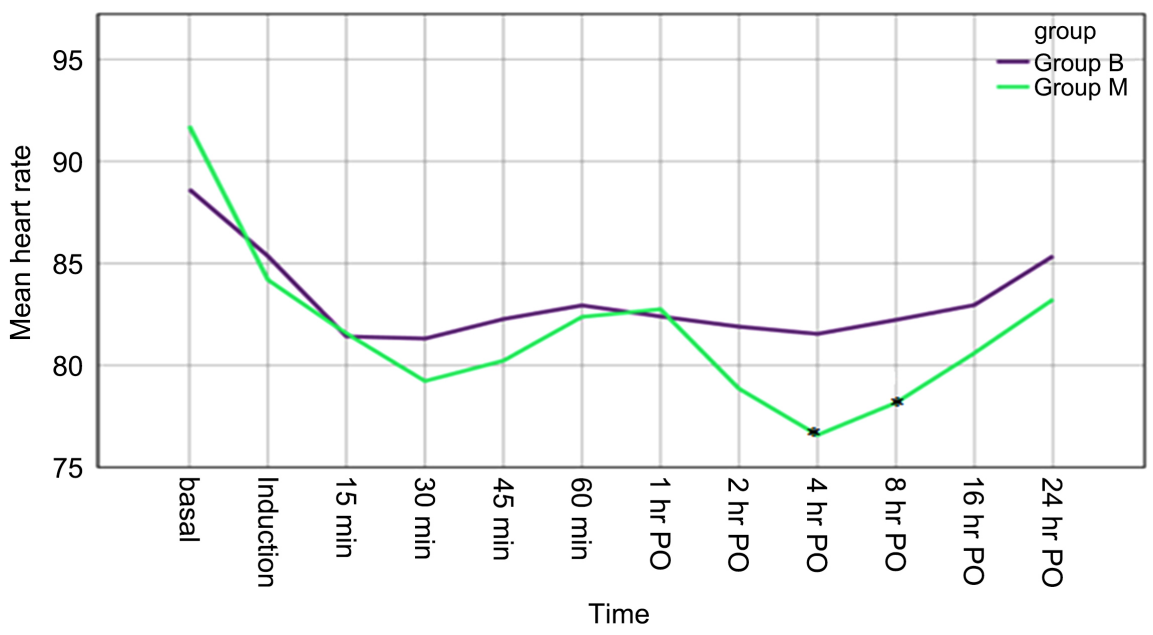

Figure 2. HR variation. Basal, intraoperative and postoperative follow-up of heart rate variation in both groups, Group B: Bupivacaine group, Group M: Magnesium group, ${ }^{\star}$ Significant when $\mathrm{p}$ value $<0.05$.

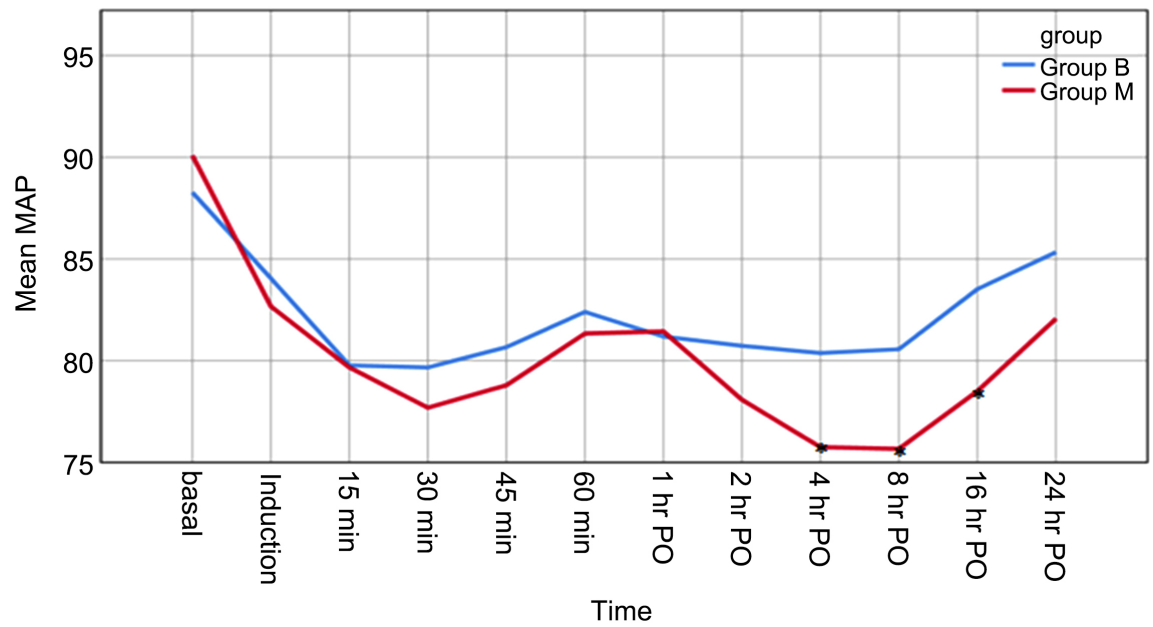

Figure 3. MAP variation. Basal, intraoperative and postoperative follow-up of MAP variation in both groups, Group B: Bupivacaine group, Group M: Magnesium group, MAP: mean arterial pressure ${ }^{\star}$ Significant when $\mathrm{P}$ value $<0.05$.

VAS was significantly lower at 2, 4, 8 and 16 hours post-operative when group $M$ was compared to group B (Table 2). However, Ramsay sedation score showed no statistically significant difference among the two groups (Figure 4).

The time of first request of analgesia was longer in group $\mathrm{M}$ than in group $\mathrm{B}$. Total postoperative pethidine consumption in the first $24 \mathrm{~h}$ post-operative showed a highly statistically significant decrease in the magnesium group in comparison to the bupivacaine group (Table 3 ).

The total dose of intraoperative fentanyl administered showed no statistically significant difference between the 2 studied groups (Table 3 ).

The incidence of PONV in the $1^{\text {st }} 24 \mathrm{~h}$ post-operative, determined by PONV impact scale score, was significantly lower when group $\mathrm{M}$ was compared to Group B (Table 4). 
Table 2. VAS score.

\begin{tabular}{cccc}
\hline VAS score & $\begin{array}{c}\text { Group B } \\
(\mathbf{n}=48)\end{array}$ & $\begin{array}{c}\text { Group M } \\
(\mathbf{n}=48)\end{array}$ & P value \\
\hline 1 h PO & $1(0-1)$ & $0(0-1)$ & 0.31 \\
$2 \mathrm{~h}$ PO & $2(1-2)$ & $1(1-1)$ & $<0.001^{\star *}$ \\
4 h PO & $2(2-3)$ & $2(1-2)$ & $<0.001^{\star *}$ \\
8 h PO & $3(3-3)$ & $3(2-3)$ & $<0.001^{\star *}$ \\
16 h PO & $4(4-5)$ & $3(3-3)$ & $<0.001^{\star *}$ \\
24 h PO & $2.5(2-3)$ & $2(2-3)$ & 0.75 \\
\hline
\end{tabular}

VAS: Visual analogue scale, Group B: Bupivacaine group, Group M: Magnesium group, PO: Post-operative, Data are expressed as median and range, ${ }^{*}$ Highly significant when $P$ value $<0.001$.

Table 3. Analgesic profile (intra-operative fentanyl $(\mu \mathrm{g})$, first request of analgesia and total post-operative pethidine $(\mathrm{mg})$ consumption in the first $24 \mathrm{~h}$ ) in the studied groups. Data are expressed as mean \pm SD.

\begin{tabular}{cccc}
\hline & $\begin{array}{c}\text { Group B } \\
(\mathbf{n}=\mathbf{4 8})\end{array}$ & $\begin{array}{c}\text { Group M } \\
(\mathbf{n}=\mathbf{4 8})\end{array}$ & P value \\
\hline $\begin{array}{c}\text { Intra-operative fentanyl }(\mu \mathrm{g}) \\
\text { consumption }\end{array}$ & $104.17 \pm 20.19$ & $102.08 \pm 14.43$ & 0.56 \\
$\quad$ Time of $\mathbf{1}^{\text {st }} \begin{array}{c}\text { request of analgesia } \\
\text { (hours) }\end{array}$ & $6.48 \pm 1.11$ & $7.29 \pm 1.34$ & $\mathbf{0 . 0 0 2 ^ { \star }}$ \\
$\begin{array}{c}\text { Total pethidine consumption in the } \\
\text { first } 24 \mathrm{~h}(\mathrm{mg}) \text { post-operative }\end{array}$ & $43.75 \pm 11.18$ & $30.31 \pm 8.84$ & $<0.001^{\star *}$ \\
\hline
\end{tabular}

Group B: Bupivacaine group, Group M: Magnesium group, ${ }^{*}$ Significant when $\mathrm{P}$ value $<0.05$, ${ }^{* *}$ Highly significant when $P$ value $<0.001$.

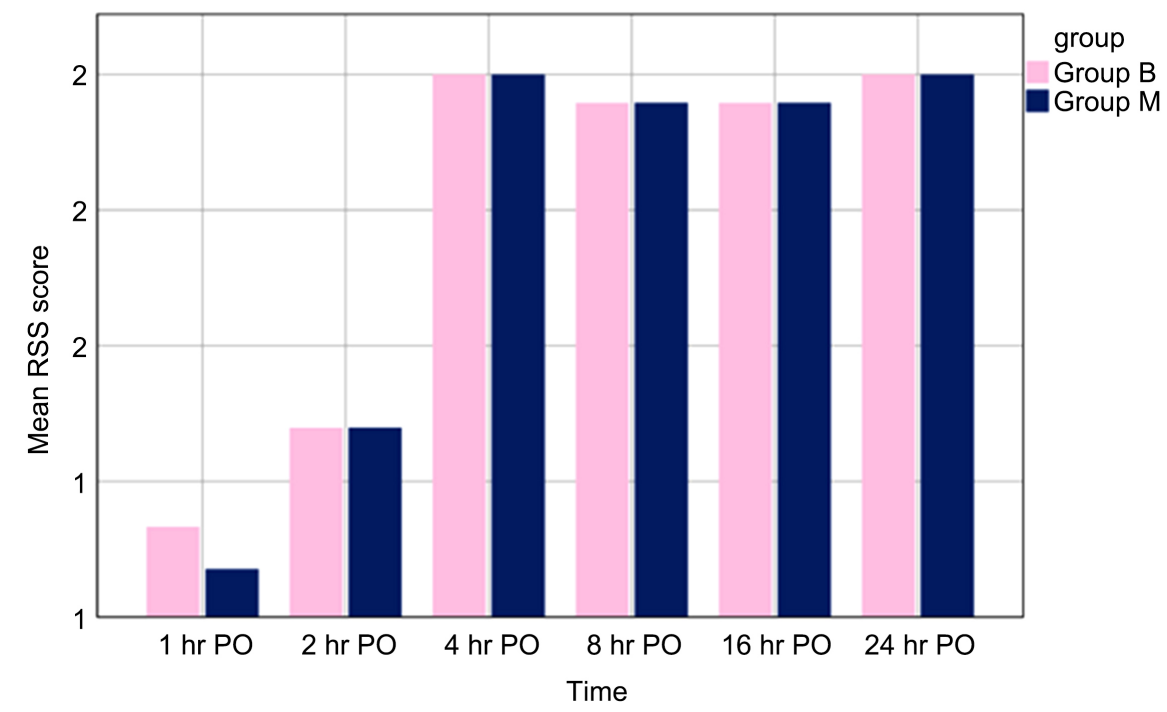

Figure 4. Ramsay sedation score. Basal and post-operative follow-up of Ramsay sedation score in both groups, RSS: Ramsay sedation score, Group B: Bupivacaine group, Group M: Magnesium group, PO: Post-operative. 
Table 4. Post-operative complications.

\begin{tabular}{cccc}
\hline & $\begin{array}{c}\text { Group B } \\
(\mathrm{n}=48)\end{array}$ & $\begin{array}{c}\text { Group M } \\
(\mathrm{n}=48)\end{array}$ & P value \\
\hline PONV impact scale score & $3(2-4)$ & $2(2-3)$ & $\mathbf{0 . 0 1 2 ^ { * }}$ \\
Post-operative hypotension & $1(1-1)$ & $1(1-1)$ & 1 \\
\hline
\end{tabular}

Post-operative complications (PONV impact scale scoreandpost-operative hypotension) in the studied groups. Data are expressed as median and range. Group B: Bupivacaine group, Group M: Magnesium group, PONV: Post-operative nausea and vomiting ${ }^{*}$ Significant when $\mathrm{p}$ value $<0.05$.

\section{Discussion}

The main finding of this study is that adding MgSo4 to bupivacaine in US guided FICB in partial thickness skin grafting procedures (in patients with second and third degree burn) decreased the post-operative VAS at 2, 4, 8 and 16 hours after surgery, prolonged the analgesic duration (delayed the time of first request of analgesia $(\mathrm{P}$ value $=0.002)$ ) and decreased the total dose of pethidine consumption in the $1^{\text {st }} 24 \mathrm{~h}$ post-operative ( $\mathrm{P}$ value $\left.=<0.001\right)$.

The demographic data and the mean duration of surgery in our study, which were statistically insignificant between the two groups, were to a great extent similar to other research and this supplied us with the uniform platform to compare the obtained results evenly.

Both groups in this study showed no statistically significant difference regarding intra operative HR and MAP. These findings are consistent with $\mathrm{Mu}$ thiah et al., who proved that adding $150 \mathrm{mg}$ magnesium to bupivacaine in 3-in-1 nerve block had no effect on intraoperative hemodynamics [12]. Also, adding MgSo4 to bupivacaine in femoral and sciatic nerve block was proved to have no impact on intraoperative hemodynamics [13] and this may be explained by the absence of systemic vasodilator effect of magnesium.

There was a significant decrease in the HR $4 \mathrm{~h}$ and $8 \mathrm{~h}$ post-operative and in the MAP $4 \mathrm{~h}, 8 \mathrm{~h}$ and $16 \mathrm{~h}$ post-operative in the magnesium group. This can be explained by less pain in the magnesium group and it is consistent with the post-operative VAS, total pethidine consumption and the first request of analgesia in our study and in Abd-Salam's study [7].

The mechanism of the analgesic action of $\mathrm{MgSO}_{4}$ can be related to a systemic action, a direct effect on the nerve or local vasoconstriction. It is primarily due to antagonism at the NMDA receptors within the dorsal horn of the spinal cord leading to prevention of central sensitization caused by peripheral nociceptive stimulation. Also, magnesium antagonizes calcium influx into nerve fibers, interferes with the release of neurotransmitter substances and potentiates the action of LA agents [14]. Another theory is that magnesium ions elevate the firing threshold of both myelinated and unmyelinated nerve fibers causing a state of hyperpolarization [15].

In our study, it was found that adding $\mathrm{MgSO}_{4}$ to bupivacaine had significant analgesic effects and this was represented by a statistically significant decrease 
in VAS scores at 2, 4, 8 and 16 hours post-operative. These results agree with the study conducted by Elshamaa and his colleagues who reported significant lower VAS scores all over the first $24 \mathrm{~h}$ post-operative in patients receiving $\mathrm{Mg}$ during femoral nerve block [16].

The current study demonstrated that there was a significant prolongation in the analgesic duration represented by the significant delay in the time of first request of analgesia when adding $\mathrm{MgSO}_{4}$ to bupivacaine. These findings correlate with Eid et al., who found that adding $250 \mathrm{mg}$ magnesium sulfate to bupivacaine in fascia iliaca compartment block significantly prolonged the duration of effective analgesia and the time offirst request of rescue analgesia [11]. Abd Elmawgoud and his colleagues also proved that adding magnesium sulfate to ropivacaine in continuous femoral nerve block significantly prolonged the time for the first request of analgesia postoperatively. [17].

On the other hand, Khairnar et al., reported no significant prolongation in the duration of postoperative analgesia when added $1.5 \mathrm{ml}$ of $15 \%$ magnesium sulfate to $21.5 \mathrm{ml}$ of $0.5 \%$ levobupivacaine in combined femoral and lateral femoral cutaneous nerve block (3). This may be the result of the low volume injected $(23 \mathrm{ml})$. The minimal effective volume oflocal anesthetics in the FICB to produce a block in $99 \%$ of caseswas $37.3 \mathrm{ml}$ for bupivacaine and $36.6 \mathrm{ml}$ for ropivacaine as describedby Helayel [18].

Also, the total dose of analgesic consumption in this study (pethidine) was significantly reduced in the first post-operative dayand this result correlates with the study conducted by Ekmekci et al., who found a highly significant decrease in the amount of tramadol consumption in patients receiving magnesium during femoral nerve block [19].

One study that disagrees with our study is the one done by Choi and his colleagueswho added $200 \mathrm{mg}$ magnesium to ropivacaine in 38 patients undergoing brachial plexsus block and found that there was no difference in VAS scores and no difference in opioid consumption post opertative [20]. These results may be due to the use of the blind technique without any usage of US, which increases the failure rate of the brachial plexsus block. This point in addition to the small sample size in the study (38 patients) could make the study unreliable. Also, administration of general anasthesia without any analgesic drug (as they did in their study) and performing the block after the surgery was completed, just before extubation leads to sensitization of the pain pathways which increases pain sensation post operative. It also contradicts the rules of preemptive analgesia which recommends giving effective analgesia before the start of any surgical stimulus to avoid sensitization of the pain pathways which once sensitized, can not be easily opposed.

Although IV magnesium produces some sedation and has anticonvulsant action in eclampsia, the current study didn't report any sedative effects when magnesium was added to bupivacaine, and this was represented by the non-significant results of the post-operative Ramsey sedation scores. This finding can be 
explained by the theory of localized action of magnesium on nociceptive pathways and this finding was also concluded by Sayed and Fathy when they added two different doses of intrathecal magnesium to bupivacaine fentanyl spinal anasthesia and did not observe any sedation either intraoperative or post operative [21].

The ideal dose of magnesium in peripheral nerve block is not yet determined. Doses from $50 \mathrm{mg}$ up to $500 \mathrm{mg}$ have been used without any neurological sequelae in human as in ELshamaa's study in which $500 \mathrm{mg}$ of magnesium sulfate was used in femoral nerve block [16]. However, it was said, in an animal study, that neurological damage such as demyelination might be linked to high doses of intrathecal magnesium administration [22]. So, we used the $250 \mathrm{mg}$ dosage to stay away from the debate about high doses of magnesium. More studies are needed to test the safety of perineural administration of high doses of magnesium and to determine a safe range of magnesium in peripheral nerve blockade.

The dose of magnesium used in our study $(250 \mathrm{mg})$ relied on data from the study of Eid et al., in which $250 \mathrm{mg}$ magnesium potentiated bupivacaine antinociception in FICB in patients with hip fracture without any side effects or neurological sequalae [11].

In our study, there was a significant decrease in the incidence of PONV, represented by the significant decrease in the PONV impact scale score in the $1^{\text {st }} 24 \mathrm{~h}$ post operative in the magnesium group. This can be explained by lower pain scores and decrease in pethidine consumption in the magnesium group. This result correlates with Al-Refaey and his colleagues who found that adding magnesium to bupivacaine in TAP block was associated with less incidence of PONV [23].

However, when Malleeswaran and his colleagues used magnesium sulfate as an adjuvant to intrathecal bupivacaine [24], they found no difference in the incidence of nausea and vomiting postoperative which may be explained by their use of NSAIDS (diclofenac) in post operative analgesia instead of pethedine (used in our study) which is famous of producing nausea and vomiting as a side effect.

Although IV magnesium can cause hypotension when it is used to treat eclampsia, our study found that there was no significant difference in the incidence of postoperative hypotension (decreased systolic blood pressure by $\geq 25 \%$ of baseline). This may be due to absence of systemic vasodilator effect of magnesium. This result correlates to Eid et al., who found that adding magnesium to bupivacaine in fascia iliaca compartment block did not affect the incidence of hypotension [11].

The current study has some limitations including: The onset of the block in both groups had not been compared (as the patients were already under general anasthesia when performing the block). The intensity of the sensory block in the distribution of femoral, LFCN and obturator nerves had not been assessed after performing the FICB (as the patients were already under general anasthesia when 
performing the block).

\section{Conclusion}

This study found that adding magnesium sulfate to bupivacaine in ultrasound guided fascia iliaca compartment block in skin grafting procedures decreases the pain scores postoperatively, prolongs the analgesic duration, delays the first request of analgesia and decreases the total analgesic consumption in the first postopertive $24 \mathrm{~h}$ without any significant side effects, so magnesium sulfate can be considered an effective and valuable adjuvant to local anesthetics in fascia iliaca compartment block.

\section{Conflicts of Interest}

The authors declare no conflicts of interest regarding the publication of this paper.

\section{References}

[1] Yang, X., Fang, Z., Liu, M., Zhang, Y., Chen, Q., Tao, K., Han, J. and Hu, D. (2019) Reconstruction of Deep Burn Wounds around the Ankle with Free Fascia Flaps Transfer and Split-Thickness Skin Graft. Journal of Burn Care \& Research, 40, 763768. https://doi.org/10.1093/jbcr/irz078

[2] Shank, E.S., Martyn, J.A., Donelan, M.B., Perrone, A., Firth, P.G. and Driscoll, D.N. (2016) Ultrasound-Guided Regional Anesthesia for Pediatric Burn Reconstructive Surgery: A Prospective Study. Journal of Burn Care \& Research, 37, 213-217. https://doi.org/10.1097/BCR.0000000000000174

[3] Khairnar, P., Agarwal, M., Verma, U.C. and Kumar, R. (2016) Comparative Efficacy of Ropivacaine and Levobupivacaine in Combined Femoral and Lateral Femoral Cutaneous Nerve Block with Adjuvant Magnesium for Post-Operative Analgesia. Indian Journal of Anaesthesia, 60, 584-589. https://doi.org/10.4103/0019-5049.187794

[4] O'reilly, N., Desmet, M. and Kearns, R. (2019) Fascia Iliaca Compartment Block. Bja Education, 19, 191-197. https://doi.org/10.1016/j.bjae.2019.03.001

[5] Amin, N.H., West, J.A., Farmer, T. and Basmajian, H.G. (2017) Nerve Blocks in the Geriatric Patient with Hip Fracture: A Review of the Current Literature and Relevant Neuroanatomy. Geriatric Orthopaedic Surgery \& Rehabilitation, 8, 268-275. https://doi.org/10.1177/2151458517734046

[6] Eizaga Rebollar, R., Garcia Palacios, M.V., Morales Guerrero, J. and Torres, L.M. (2017) Magnesium Sulfate in Pediatric Anesthesia: The Super Adjuvant. Pediatric Anesthesia, 27, 480-489. https://doi.org/10.1111/pan.13129

[7] Abd-Elsalam, K.A., Fares, K.M., Mohamed, M.A., Mohamed, M.F., El-Rahman, A.M.A. and Tohamy, M.M. (2017) Efficacy of Magnesium Sulfate Added to Local Anesthetic in a Transversus Abdominis Plane Block for Analgesia Following Total Abdominal Hysterectomy: A Randomized Trial. Pain Physician, 20, 641-647. https://doi.org/10.36076/ppj.2017.7.641

[8] Haefeli, M. and Elfering, A. (2006) Pain Assessment. European Spine Journal, 15, 17-24. https://doi.org/10.1007/s00586-005-1044-X

[9] Namigar, T., Serap, K., Esra, A.T., Özgül, O., Can, Ö.A., Aysel, A. and Achmet, A. 
(2017) The Correlation among the Ramsay Sedation Scale, Richmond Agitation Sedation Scale and Riker Sedation Agitation Scale during Midazolam-Remifentanil Sedation. Brazilian Journal of Anesthesiology (English Edition), 67, 347-354. https://doi.org/10.1016/j.bjane.2016.07.002

[10] Myles, P.S. and Wengritzky, R. (2012) Simplified Postoperative Nausea and Vomiting Impact Scale for Audit and Post-Discharge Review. British Journal of Anaesthesia, 108, 423-429. https://doi.org/10.1093/bja/aer505

[11] Eid, H., Shafie, M. and Youssef, H. (2012) Magnesium Prolongs the Duration of Analgesia after a Bupivacaine Fascia Iliaca Compartment Block. Ain-Shams Journal of Anaesthesiology, 5, 233-238.

[12] Muthiah, T., Arora, M.K., Trikha, A., Sunder, R.A., Prasad, G. and Singh, P.M. (2016) Efficacy of Magnesium as an Adjuvant to Bupivacaine in 3-in-1 Nerve Block for Arthroscopic Anterior Cruciate Ligament Repair. Indian Journal of Anaesthesia, 60 , 491-495. https://doi.org/10.4103/0019-5049.186018

[13] Alzeftawy, A.E. and El-Daba, A.A. (2016) Cold Bupivacaine versus Magnesium Sulfate Added to Room Temperature Bupivacaine in Sonar-Guided Femoral and Sciatic Nerve Block in Arthroscopic Anterior Cruciate Ligament Reconstruction Surgery. Anesthesia, Essays and Researches, 10, 667-673. https://doi.org/10.4103/0259-1162.183162

[14] Soave, P.M., Conti, G., Costa, R. and Arcangeli, A. (2009) Magnesium and Anaesthesia. Current Drug Targets, 10, 734-743. https://doi.org/10.2174/138945009788982487

[15] Goyal, P., Jaiswal, R., Hooda, S., Goyal, R. and Lal, J. (2008) Role of Magnesium Sulphate for Brachial Plexus Analgesia. Internet Journal of Anesthesiology, 21, 284-290. https://doi.org/10.5580/1a90

[16] Elshamaa, H.A., Ibrahim, M. and Eldesuky, H.L. (2014) Magnesium Sulfate in Femoral Nerve Block, Does Postoperative Analgesia Differ? A Comparative Study. Egyptian Journal of Anaesthesia, 30, 169-173. https://doi.org/10.1016/j.egja.2013.10.005

[17] Elmawgoud, A., Badawy, A., Elkassem, S.A. and Rashwan, D. (2008) Effect of Addition of Magnesium Sulphate and Fentanyl to Ropivacaine Continuous Femoral Nerve Block in Patients Undergoing Elective Total Knee Replacement. Journal of Medical Sciences, 8, 395-399. https://doi.org/10.3923/jms.2008.395.399

[18] Helayel, P.E., Lobo, G., Vergara, R., Conceição, D.B.D. and Oliveira Filho, G.R.D. (2006) Effective Volume of Local Anesthetics for Fascia Iliac Compartment Block: A Double-Blind, Comparative Study between 0.5\% Ropivacaine and 0.5\% Bupivacaine. Revistabrasileira de Anestesiologia, 56, 454-460. https://doi.org/10.1590/S0034-70942006000500003

[19] Ekmekci, P., Bengisun, Z.K., Akan, B., Kazbek, B.K., Ozkan, K.S. and Suer, A.H. (2013) The Effect of Magnesium Added to Levobupivacaine for Femoral Nerve Block on Postoperative Analgesia in Patients Undergoing ACL Reconstruction. Knee Surgery, Sports Traumatology, Arthroscopy, 21, 1119-1124. https://doi.org/10.1007/s00167-012-2093-4

[20] Choi, I.G., Choi, Y.S., Kim, Y.H., Min, J.H., Chae, Y.K., Lee, Y.K., Ahn, S.W., Kim, Y.S. and Lee, A. (2011) The Effects of Postoperative Brachial Plexus Block Using MgSO4 on the Postoperative Pain after Upper Extremity Surgery. The Korean Journal of Pain, 24, 158-163. https://doi.org/10.3344/kjp.2011.24.3.158

[21] Sayed, J.A. and Fathy, M.A. (2012) Maternal and Neonatal Effects of Adding Two Different Doses of Intrathecal Magnesium Sulphate to Bupivacaine Fentanyl Spinal 
Anesthesia in Mild Preeclamptic Patients Undergoing Caesarean Section. The Journal of American Science, 8, 435-441.

[22] Ozdogan, L., Sastim, H., Ornek, D., Postaci, A., Ayerden, T. and Dikmen, B. (2013) Neurotoxic Effects of Intrathecal Magnesium Sulphate. Brazilian Journal of Anesthesiology, 63, 139-143. https://doi.org/10.1016/j.bjane.2012.02.002

[23] Al-Refaey, K., Usama, E. and Al-Hefnawey, E. (2016) Adding Magnesium Sulfate to Bupivacaine in Transversus Abdominis Plane Block for Laparoscopic Cholecystectomy: A Single Blinded Randomized Controlled Trial. Saudi Journal of Anaesthesia, 10, 187-191. https://doi.org/10.4103/1658-354X.168821

[24] Malleeswaran, S., Panda, N., Mathew, P. and Bagga, R. (2010) A Randomised Study of Magnesium Sulphateas an Adjuvant to Intrathecal Bupivacaine in Patients with Mild Preeclampsia Undergoing Caesarean Section. International Journal of Obstetric Anesthesia, 19, 161-166. https://doi.org/10.1016/j.ijoa.2009.08.007 